\title{
The Danish Alzheimer Intervention Study: Rationale, Study Design and Baseline Characteristics of the Cohort
}

\author{
G. Waldemar $^{a} \quad$ F.B. Waldorff ${ }^{a, b} \quad$ D.V. Buss ${ }^{a} \quad$ A. Eckermann ${ }^{a} \quad$ N. Keiding ${ }^{c}$ \\ S. Rishøj ${ }^{a} \quad$ V.Siersma ${ }^{b} \quad$ J. Sørensen ${ }^{d} \quad$ L.V. Sørensen ${ }^{a} \quad$ A. Vogel $^{a}$ \\ ${ }^{a}$ Memory Disorders Research Group, Department of Neurology, Rigshospitalet, Copenhagen University Hospital, \\ ${ }^{b}$ Research Unit and Department of General Practice and ' Department of Biostatistics, Institute of Public Health, \\ University of Copenhagen, and ${ }^{\mathrm{d} C e n t r e}$ for Applied Health Services Research and Technology Assessment, \\ University of Southern Denmark, Copenhagen, Denmark
}

\section{Key Words}

Alzheimer's disease $\cdot$ Dementia $\cdot$ Randomized controlled

trial $\cdot$ Study design $\cdot$ Counselling $\cdot$ Psychosocial

intervention · Support · Caregiving

\begin{abstract}
Background: There is a lack of appropriately designed trials investigating the efficacy of psychosocial interventions for patients with mild dementia and their family caregivers. This paper reports the rationale and design of the Danish Alzheimer Disease Intervention Study and baseline characteristics of the cohort. Methods: The study was a 1-year multicentre randomized controlled rater-blinded trial with randomization to follow-up and a multifaceted semitailored intervention programme or to follow-up only (with extension of follow-up to 3 years). The intervention included a counselling programme, teaching courses, written information and logbooks. The outcomes included clinical efficacy parameters, patient satisfaction and health economic consequences. Results: A total of 330 patients and their 330 caregivers were included during a period of 18 months. The majority (65.2 \%) of the caregivers were spouses. At inclusion
\end{abstract}

the mean age of the patients and caregivers was 76.2 and 66.0 years, respectively. Conclusion: The study will explore the added value of a multifaceted intervention programme and contribute to the design of future interventions for patients with mild dementia and their caregivers.

Copyright $\odot 2010$ S. Karger AG, Basel

\section{Introduction}

Alzheimer's disease (AD) and other dementia disorders are characterized by progressive decline in cognitive, social and occupational function and are often associated with affective symptoms and behavioural disturbances. The majority of the patients are living in their own homes and require increasing assistance and supervision from caregivers, often a spouse. The role as a family caregiver for a patient with dementia is associated with a greater risk of developing stress and somatic and psychiatric health problems [1-3]. Several studies have indicated that counselling and psychosocial interventions for caregivers may have a significant positive effect in patients with moderate to severe $\mathrm{AD}[4-6]$ as well as in their caregivers $[5,7-16]$.

\section{KARGER}

Fax +41613061234 E-Mail karger@karger.ch www.karger.com
(C) 2010 S. Karger AG, Basel

0251-5350/11/0361-0052\$38.00/0

Accessible online at:

www.karger.com/ned
Prof. Gunhild Waldemar, MD

Memory Disorders Research Group, Department of Neurology, Section 2082

Rigshospitalet, Copenhagen University Hospital

9 Blegdamsvej, DK-2100 Copenhagen (Denmark)

Tel. +45 3545 2580, Fax +453545 2626, E-Mail gunhild.waldemar@ rh.regionh.dk 
In general, however, results have been inconsistent, the quality of studies has been poor, and there is a need for appropriately designed trials [17]. For policy makers and service planners, who work with carer and patient support in dementia, good quality evidence is crucial for identifying who would benefit from the service and when. While there is an increasing awareness of the importance of early and continuous support and care, the majority of the patients have no or little access to diagnostic evaluation, treatment, and follow-up during the course of their disease $[18,19]$. With increased awareness and better diagnostic methods many patients with progressing neurodegenerative dementia disorders are now diagnosed in the very early phase of their disease. Patients with very mild dementia often have nearly full autonomy and may request more attention and specific counselling programmes directed towards their own needs. Hence, it is necessary to develop and validate support programmes, which focus specifically on the needs of patients with mild dementia and their caregivers, and which include psychosocial support for the patient as well as for the caregiver. The aim of the Danish Alzheimer Disease Intervention Study (DAISY) was to evaluate and explore clinical effect, patient satisfaction and health economic consequences of a multifaceted and semitailored intervention programme in patients with mild dementia and their caregivers, in whom follow-up secured referral to conventional local support programmes where available and relevant.

We hypothesized that the multifaceted and semitailored intervention programme offered to the patients and their primary caregivers during the first year after the diagnosis might prevent the emergence of depressive symptoms and improve the quality of life in patients as well as in caregivers, and perhaps even stabilize the patients' cognitive function for some time. This paper reviews current methodological issues in psychosocial interventions and reports the rationale and design of the DAISY study, and the baseline characteristics of the cohort.

\section{Material and Methods}

\section{Study Design}

The study design and reporting adhere to the Consolidated Standards for Reporting Trials Statement (www.consortstatement.org) [20]. The study design was compatible with the quality criteria and recommendations proposed by the Cochrane systematic review on support for carers of people with $\mathrm{AD}$, which was available at the time of the initiation of the study [21] and later updated [22].

Danish Alzheimer Intervention Study

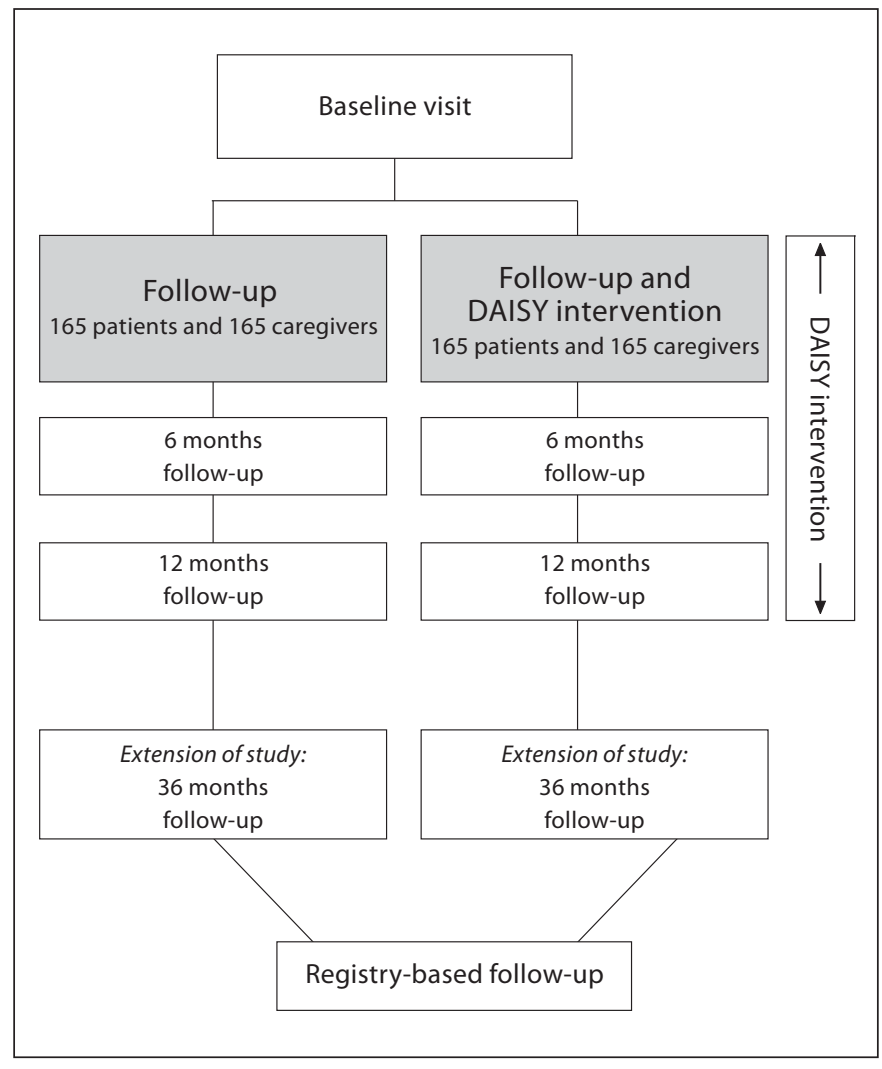

Fig. 1. DAISY trial design. The bar illustrates the duration of the intervention in the intervention group. The primary efficacy parameters were defined at 1 year after baseline.

As shown in figure 1, the study was designed as a 1-year multicentre randomized controlled rater-blinded trial (RCT) with 1:1 randomization to follow-up only or to follow-up with the addition of the DAISY intervention, a multifaceted semitailored intervention programme, described in detail below. Two years after study start supplementary funding was obtained to extend the follow-up with a study visit 3 years after inclusion.

To randomize participants we used a central allocation process by a third party unaware of and concealed for the DAISY investigators. The allocation process was initiated after patient and caregiver identity and key baseline data had been registered in the central project office. The randomization was done using a computer programme (Stat-Direct version 2.3.7). We used a random block size algorithm to prevent imbalance between the allocation groups. Patients were stratified by centre, MMSE score (20-23; 24-30) and use (or nonuse) of symptomatic antidementia drugs. The assignment to group was done via letters from the central office to the local study coordinators. As described below, a range of primary and secondary quantitative outcome measures from standardized tests and scales, from interview data or from registry-based information were collected at baseline and at 6, 12 and 36 months. The randomization code and study results were not opened until after the last patient had completed the visit at 3 years. In the intervention group, patient and caregiver compliance 


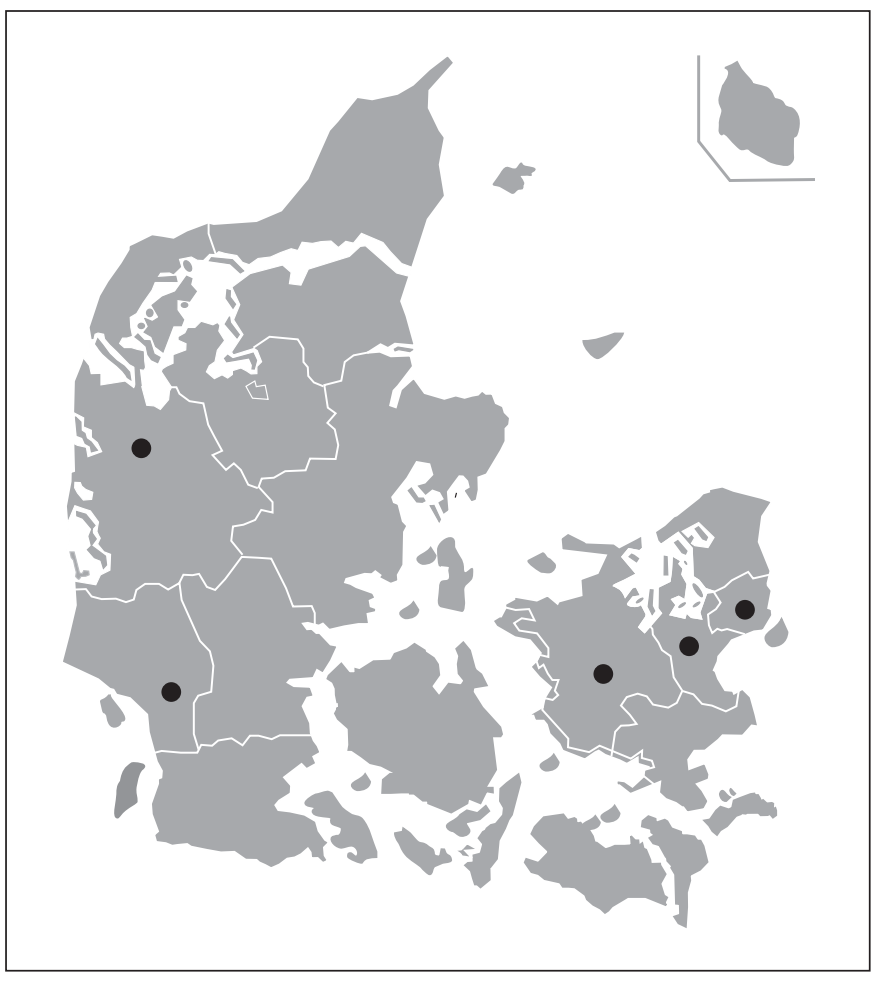

Fig. 2. Map of Denmark showing the 5 counties involved in the DAISY study: Ribe, Ringkøbing, Vestsjaelland and Roskilde counties, and central Copenhagen (Frederiksberg and Copenhagen municipalities).

and satisfaction with the intervention programme, and qualitative aspects of the intervention were assessed in separate substudies.

\section{Patients}

Recruitment. The study was conducted in 5 counties, representing rural and urban districts, in Denmark (fig. 2), and inclusion took place in 1 centre in each county during a period of 18 months. In each of the 5 counties information regarding the project was provided to all general practitioners, to private practice neurologists and psychiatrists, as well as to all hospital departments involved in diagnostic evaluation of patients with dementia. The local study coordinator and a designated physician in each of the local memory clinics assessed patients regarding inand exclusion criteria.

Inclusion Criteria. The study included community-dwelling patients with a clinical diagnosis of probable $\mathrm{AD}$, mixed $\mathrm{AD}$ with vascular components or dementia with Lewy bodies (DLB), established within the past 12 months; age $\geq 50$ years; mild dementia with MMSE score $\geq 20$; a primary caregiver with close contact to the patient who was willing to participate in the study and the intervention; and informed consent from the patient and the caregiver. All patients met DSM-IV [23] for dementia and the NINCDS-ADRDA criteria for probable AD [24] or the McKeith criteria for DLB [25]. Participants classified as mixed AD were patients with probable AD who had vascular changes on cranial CT, which may contribute to their symptoms.

Exclusion Criteria. Patients with severe somatic or psychiatric comorbidity (including impaired hearing or vision), which would significantly impair their cooperation with the programme, were excluded. Patients participating in other intervention studies and patients living in a nursing home at baseline were also excluded.

\section{Primary Caregivers}

A primary caregiver was defined as the informal caregiver who was the main person responsible for the informal care to the patient and who had regular contacts (at least weekly) with the patient. For patients who had $>1$ primary caregiver, the invitation to join this study was given to only 1 person, at the patient's choice.

\section{Baseline and Follow-Up Visits}

Patients and their primary caregivers participated together in all visits. The baseline visit took place prior to randomization and was performed by the local study coordinator in the local memory clinic. The follow-up visits were home visits performed at 6,12 and 36 months by independent raters unaware of the randomization code. The raters were not involved in the intervention programme, and they were not employed in the same institutions as the study coordinators and counsellors. Patients and caregivers were instructed to try not to reveal which treatment arm they were in. The efficiency of concealment was checked using a questionnaire to the raters at the end of each follow-up visit. None of the raters visited the same patient-caregiver couple more than once.

\section{Drop-Outs}

For patients dropping out of the study, the date and reason for dropout was registered. If a patient dropped out for whatever reason, the caregiver was not allowed to continue in the study. If a primary caregiver dropped out, she/he was replaced with another primary caregiver if possible, in order to continue assessment of proxy-rated parameters (whereas scales rating caregiver health status were discontinued). If no replacement was possible, only the patient continued in the study, and proxy-rated assessments were discontinued.

\section{Roles and Training of Study Coordinators, Raters and}

Monitors

In each of the 5 centres a study coordinator was responsible for recruitment, baseline assessments, implementation of the multifaceted and semitailored intervention, all counselling sessions and project coordination. The study coordinators were all designated specialist nurses with several years of experience in the field of dementia and in counselling. Prior to the initiation of the study the study coordinators participated in a 4-day centralized course, where they were instructed in the rationale and design of the study, in the intervention programme, in basic concepts of patient and caregiver intervention, and in the concepts and objectives of the specific counselling programme applied in this study. The course also contained formalized teaching of communication and counselling. Throughout the study intervention period, the study coordinators were offered supervision on a regular basis at 8 centralized follow-up sessions and at regular site visits by specialists from the coordinating study centre. The raters were nurses, therapists and other health professionals from the local municipalities or hospitals. They were responsible for follow-up of all patients 
and assessments at 6,12 and 36 months. Both study coordinators and raters participated in centralized training sessions for the assessment of primary and secondary efficacy parameters. Central study monitors observed the progress of the study in each centre and checked case report forms for completeness and consistency throughout the study.

\section{The DAISY Intervention: A Multifaceted and Semitailored} Intervention Programme

The novel multifaceted and semitailored intervention programme was designed to comprise counselling, information and support to patients with mild dementia as well as to their primary caregivers during the initial months after a diagnosis had been established (fig. 3). The objective of the programme was to prevent the emergence of depressive symptoms and further impairment of health-related quality of life in patients as well as in caregivers, and perhaps even stabilize cognitive function in the patients for some time. The philosophy was to focus on positive resources, intact functions and retained skills and activities that the patients could still take part in. Administered by the local study coordinator in each centre, the programme was carried out in the intervention group only and initiated within the first month after inclusion. Having 5 key components, part of the intervention was tailored to the needs of the individual patient and/or caregiver, while other parts of the programme were based on group intervention. The participants were encouraged to take advantage of all components in the intervention programme as much as possible. Counselling sessions were planned on a running basis, while group-based teaching courses were scheduled to start when a sufficient number of participants had been allocated to the intervention arm. Thus, for logistical reasons the duration of the full intervention programme could vary from 8 to 12 months.

\section{Counselling Sessions}

The counselling aimed to prevent or reduce depressive symptoms, impairment of health- related quality of life and loss of social network. The counselling programme was based on constructivist principles [26]: the principles and methodology were anchored on the dynamics that characterizes the patient and the caregiver's everyday life. The counselling was based on a philosophical approach in which each patient or caregiver was given the possibility of expressing his/her own life story and what is of personal importance and of great value to the individual. The counsellor offered the patient and the caregiver guidance with common decision-making, advice and activities that help the participants to construct a meaningful life.

At the initial counselling visit well-structured written notes were established. The notes were constructed to reflect the individual strengths and needs of the patient and the caregiver in 4 related areas: daily life, social network, pleasures and activities. The written notes were used to focus follow-up sessions, with the aim of improving coping strategies and to empower the patient and caregiver to focus on the positive factors and resources in their lives, according to the principles of self-validation. Self-validation is the process of recognizing and transcending the sense of self by various means to appreciate the unconditional value and meaning of our personal existence [27].

The counselling sessions were conducted by the local study coordinator in the home of the patient or in the hospital-based memory clinic. It was composed of: (a) 2 sessions with the patient

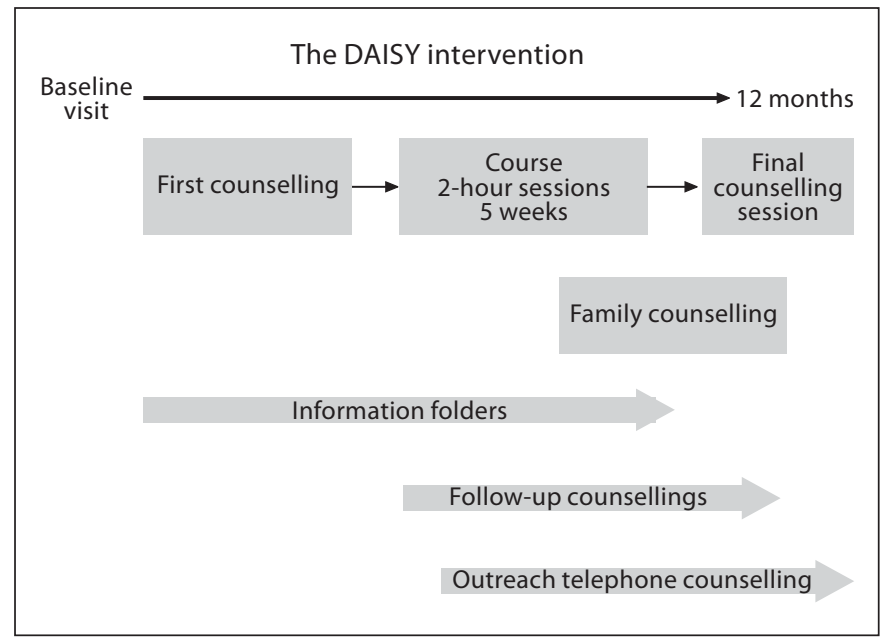

Fig. 3. Schematic illustration of the temporal relationship between the components of the DAISY intervention.

and caregiver, (b) 2 sessions with the patient alone, (c) 2 sessions with the caregiver alone, and (d) 1 optional network session with the patient, caregiver and family network.

\section{Courses}

The aim of the courses was to provide patients and caregivers with basic information about dementia and its consequences and about living and coping with dementia. The courses also aimed to provide a forum for patients and caregivers to exchange experiences and coping strategies. Two parallel lines were aimed at patients and caregivers, respectively. The courses for patients took place simultaneously with the courses for their caregivers, but in a separate classroom. In each line the course programme included 5 scheduled sessions for groups of 12 participants. Each session included a standardized agenda with information on key topics related to dementia: general information about dementia, legal aspects, living with dementia, support to people with dementia and their caregivers, and a summary session with miscellaneous topics. The sessions were supported by written information produced specifically for patients and caregivers in this study. Furthermore, support group activities with open agendas were conducted at the end of each session. Here, the patients (or caregivers) could discuss topics and questions of their interest and get informal advice from other patients (or caregivers). All courses were coordinated by the local study coordinator, and local health professionals in the field of dementia were invited as teachers. Volunteers were invited to assist the teacher in the course sessions for patients.

\section{Information Folder}

A comprehensive information folder with structured information sheets about dementia and related aspects was developed specifically for this study and provided to all participants in the intervention group. The aim of the folders was to provide the participants with written information, which would support the information given at counselling sessions and teaching courses 
Table 1. Primary and secondary efficacy parameters

Primary efficacy parameters

Patient:

Depressive symptoms (Cornell's depression scale) [40]

Proxy-rated health-related quality of life (EuroQoL VAS) [41] MMSE [42]

Caregiver:

Depressive symptoms (Geriatric Depression Scale, GDS-30) [43]

Health-related quality of life (EuroQoL VAS) [41]

Secondary efficacy parameters

Health-related quality of life in patients (proxy-rated EuroQoL 5D and VAS, Quality of life Alzheimer's disease scale QOL-AD) [41, 44]

Health-related quality of life in caregiver (EuroQoL 5D and VAS) [41]

Behavioral symptoms: Neuropsychiatric Inventory Questionnaire (NPI-Q) $[45,46]$

Activities of daily living (ADCS-ADL) [47]

Insight scale [48]

Resource utilization in patient and caregiver (Resource Utilization in Dementia, RUD) [49]

Health care resource utilization and costs

Registry-based assessment of health care utilization and key social and health-related events from 12 months before inclusion and during 5 years of follow-up:

Time to nursing home placement and death

Number of hospital contacts in patient and caregiver

Comorbidity and use of drugs in patient and caregiver

Patient and caregiver content with intervention, public services and network

Patient and caregiver knowledge and attitudes about key issues in dementia

and also to serve as a reference guide later in the course of the dementia disease after completion of the intervention programme. There were separate and different folders for patients and for caregivers. The folders contained chapters on causes of dementia, diagnosis and treatment, legal aspects in relation to dementia, and sources and contact details for social support.

\section{Outreach Telephone Counselling}

The aim of outreach telephone counselling was to ensure regular contact and to follow up on issues discussed during the individual counselling sessions. At inclusion, patients and caregivers decided which one of them should receive the calls. During the intervention phase the study coordinator contacted the participants approximately 5-8 times with 3- to 4 -week intervals. The calls focused on issues discussed at the individual sessions and education courses, but sometimes the conversations included other issues relevant to the individual participant.

\section{Logbook}

Patients and caregivers were each supplied with a logbook where they were free to write information and thoughts about their daily life. The logbooks aimed to encourage patients and caregivers to make notes about their daily life and prepare for the counselling sessions. Use of the logbooks in the counselling sessions was optional.

\section{Follow-Up Intervention}

Attempts were made to provide equal treatment for both intervention and control participants in all respects other than the add-on study intervention. At every study visit participants in both groups were interviewed about their current symptoms and daily life and informed about available support programmes (if any) in their local community, and they were free to participate in those during the study. Participation in other local support activities was registered for both groups. Identified special needs led to referral to local care facilities when available and relevant.

\section{Primary Outcome Parameters}

Since this is one of the first studies to examine the effect of support and counselling programmes in patients with very mild dementia, no consensus exists with respect to gold standards for documenting efficacy. The selection of primary and secondary efficacy parameters (listed in table 1) for this study was based on the specific aims of the intervention and on the outcome in previous similar intervention studies in patients with more advanced dementia. Although the study follow-up was extended to 3 years, the primary outcome parameters were defined for the patients and caregivers at the end of year 1 . In the patients the primary outcomes were the emergence of depressive symptoms, proxy-rated health-related quality of life and global cognitive performance (change from baseline at 1 year). In the caregivers the primary outcomes were emergence of depressive symptoms and self-rated health-related quality of life (change from baseline at 1 year).

\section{Other Quantitative Outcome Parameters}

In addition, a wide range of secondary outcome variables were included (table 1). Two questionnaires, 1 for the patient and 1 for the caregiver, were used to assess additional health issues, social network, content, legal aspects, knowledge of dementia and driving. The caregiver questionnaire was completed by the caregiver, while the patient questionnaire was completed by the rater and based on an interview with the patient. Long-term follow-up data for mortality, morbidity, institutionalization and health care utilization will be drawn from national registries. The methods for assessing health care costs and private costs are described in a separate paper [28].

\section{Data Analysis}

Comparisons of patient and caregiver characteristics and study outcomes at baseline between randomization groups will be done by $t$ tests for continuous variables and $\chi^{2}$ tests for categorical variables. At the 6-, 12- and 36-month follow-up, the outcomes in the 2 randomization groups will be evaluated by the mean of their observed values and the mean change from baseline; comparison between randomization groups will be done by $t$ tests in which subjects with missing values are omitted. Additionally, the difference in development of the primary outcomes over the follow-up period between randomization groups will be investigated in linear mixed models. Here, to adjust for possible bias because of differential dropout from the study, the assessment available at the 6-, 12- and 36-month follow-up will be weighted by the inverse of an estimate of the probability of staying in the study $[29,30]$. These probabilities will be estimated from the data in logistic regression models for death and dropout with the dyad's characteristics and the observed primary outcomes from previous visits as covariates. Difference in mortality and institutionalization between the randomization groups will be evaluated by a hazard ratio from a Cox regression model. Statistical significance will be assessed at a 5\% level. Adjustment for multiple testing will be done by the Bonferroni method. 
Power Calculations

Based on mean scores and score variations for MMSE, EuroQoL VAS, Cornell Depression Scale and GDS from previous studies in other similar AD populations $[15,31-33]$ we estimated that a group size of 165 was needed in order to detect a minimum effect size (defined as the difference between groups for mean change from baseline to 1 year in observed scores) of 1.2 (MMSE), 2.0 (Cornell), 1.8 (GDS), 6.0 (EuroQoL VAS) with type I error 5\% and type II error $10 \%$. The calculations were based on an estimated dropout rate of $20 \%$ at year 1 . The minimum effect sizes were partly arbitrarily set, partly defined from outcomes in previous intervention studies $[15,31,32]$.

\section{Compliance}

In the intervention group compliance was defined as the rate of adherence with the schedule for the major components of the multifaceted intervention programme. Thus, patients with satisfactory compliance were defined as patients who had participated with their caregivers in at least 3 counselling sessions (not including the optional network session) and in at least 3 teaching course sessions.

Evaluation of Participants' Satisfaction with the Intervention Programme

In the intervention group evaluation forms were used at 12 months to quantitatively assess patient and caregiver satisfaction concerning each component in the add-on intervention programme and overall satisfaction with the programme.

\section{Qualitative Study}

A separate qualitative study used individual semistructured in-depth interviews of selected patients and caregivers from the intervention group in order to study the experienced outcome of the intervention in qualitative terms. The intervention group evaluation and the qualitative study were conducted and reported prior to the completion of follow-up in the RCT [34].

\section{Ethics}

The DAISY trial was conducted in accordance with the Helsinki declaration and evaluated by the local Scientific Ethics Committee [j. nr. (KF) 02-005/04]. All patients and caregivers gave informed consent to participation in the study, which was approved by the Danish Data Protection Agency (j. nr. 200341-3178) and registered in the Clinical Trial Database (www. controlled-trials.com/ISRCTN74848736).

\section{Results}

In total 330 patients (151 males and 179 females), of whom $30.9 \%$ lived alone, were included in the study during a period of 18 months. Their mean age was 76.2 years (range $=54-92$ ), while the mean age of the 330 primary caregivers (110 males and 220 females) was 66.0 years (range $=22-90$ ). The majority of the caregivers were spouses (65.2\%). Of the 330 patients, $72.4 \%$ had been $\mathrm{di}-$ agnosed as having $\mathrm{AD}, 25.9 \%$ had mixed $\mathrm{AD}$, and $2.7 \%$ met the criteria for DLB. Most patients received antidementia treatment with either a cholinesterase inhibitor (93.3\%) or memantine (1\%).

\section{Discussion}

To our knowledge, this prospective study is the largest randomized controlled trial to date to investigate the efficacy and cost-effectiveness of an intensive support and counselling programme for patients in the early phase of $\mathrm{AD}$ and their caregivers. With access to national registries for health and social care, the study offers a unique opportunity to follow the long-term outcome and benefits of the intervention.

It is well recognized that caring for a family member with dementia is a challenging task associated with impaired quality of life, and increased risk for depression and other health problems $[1,2]$, and that monitoring caregiver burden and quality of life is an important and integral task of dementia care. The beneficial effect of a wide range of interventions in order to enable caregiver coping, reduce caregiver burden and improve caregiver quality of life is well recognized from clinical practice and numerous previous studies. The most common interventions are training and education programmes, information-technology-based support, respite care, home care service, support groups and technical aids [5, 7-12]. Most, however, are directed towards caregivers to patients with moderate to severe dementia.

With advancing medicine and increased public awareness of dementia more patients are diagnosed in the early phase of dementia, when they may still have a relatively well preserved autonomy and often request individual counselling, information and training. Thus, a psychosocial intervention programmes in mild dementia must be adjusted to the special needs of caregivers and at the same time include interventions directed towards the patient.

\section{The DAISY Intervention Programmes}

The initiation of this study was based on experiences in our own memory clinic from counselling and teaching programmes for patients with mild dementia and their caregivers. We designed the DAISY intervention as a multifaceted and semitailored intervention programme, which aimed to prevent the emergence of depressive symptoms and impairment of health-related quality of life in patients as well as in caregivers, and perhaps even stabilize the functional status for some time. The programme comprised counselling, information and sup- 
port to patients with mild dementia as well as to their primary caregivers during the initial months after a diagnosis had been established. Rather than focusing on compensation for lost functional abilities, the philosophy of the counselling programme was to focus on positive resources, intact functions and retained skills, and activities that the patients could still take part in. In order to ensure regular contacts and to follow up on issues discussed in the individual counselling sessions outreach telephone counselling was conducted at regular intervals. The aim of the courses was to provide patients and caregivers with basic information about dementia and its consequences and about living and coping with dementia. The courses also aimed to provide a forum for patients and caregivers to exchange experiences and coping strategies. The counselling and courses were supported by written information and log books to be kept by the patients and caregivers. A unique feature of the programme was the consistent 2-lined design with activities and information specifically directed towards the patients as well as the caregivers. Another unique feature was the semitailored design with some components adapted to the needs of the individual patient or caregiver and with other components common for all participants. The inclusion of the family network in one of the counselling sessions, at the discretion of the patient, aimed to ensure information to all, to prevent stigmatization, to identify important resources in the network and to enable the caregiver to recruit a larger network, when needed.

The intention of the programme was not only to investigate the short-term effect in the period where the intervention took place. By trying to empower both patients and caregivers to understand their symptoms and situations better, and by teaching coping strategies, the intervention and counselling was intended to have a long-term effect.

\section{Follow-Up}

For ethical reasons and in order not to leave any participants in the control group without any intervention except blinded rating, both groups received a standardized follow-up intervention. At every study visit participants in both groups were interviewed about their current symptoms and daily life and informed about available support programmes (if any) in their local community, and they were free to participate in those during the study. Any specific and urgent needs identified by the study raters were handled by referral to the general practitioner or local care programmes, when relevant. Thus, these attempts to provide equal treatment of both inter- vention and control participants in all respects other than the DAISY intervention left all participants with a service well above the level of usual care, as patients with dementia in Denmark, if diagnosed, are often left without any follow-up and without any systematic monitoring of caregiver needs $[18,19]$.

\section{Selection of Patients}

We included only patients with mild recently diagnosed dementia and only patients who had been offered a conventional diagnostic evaluation by a local specialist in dementia. By requiring appropriate diagnostic evaluation we wanted to prevent patients with questionable dementia and nonprogressive cognitive disorders from entering our programme. We did not allow patients with frontotemporal dementias in the programme, as they often have other needs. They may have difficulties in cooperating with the programme, and it may be difficult to mix patients with different disorders in the same sessions. Patients and caregivers were invited to the study regardless of their expected or expressed needs for intervention. Thus, the inclusion into the study was not restricted to patients and caregivers with active help-seeking behaviour. Participation in the study programme was quite demanding, particularly for those entering the DAISY intervention group. Adherence to the many counselling meetings and courses may be difficult for some, particularly for those with impaired somatic health status, busy caregivers, and for those living far away from the study centre. By the mere fact that a diagnosis and caregivers were required for entering the study, our population was selected. However, based on previously reported data on self-rated health and social performance $[35,36]$, the profile of patients and caregivers in our study was similar to that of typical drug trials and other clinical cohorts in mild AD [31,32,37].

\section{Outcome Parameters}

There was only little guidance from the literature for the selection of primary outcome parameters and for a priori sample size calculations. Our choices were based on the objectives of the DAISY intervention, on results in previous psychosocial intervention studies for caregivers to patients with more advanced dementia and on drug trials in mild AD. However, a wide range of additional quantitative outcome parameters were included. A unique feature of the study is the potential for follow-up of the cohort far beyond the actual study visits by using information in the systematic and comprehensive Danish health care registries. 
Assessment of Efficacy in Psychosocial Interventions

In a recent systematic review aimed to assess the effectiveness of interventions based on information and support provision for informal caregivers of people with dementia in community settings 44 randomized studies were included according to assessment of quality and relevance [17]. Overall the methodological quality of the studies was poor. For instance, only 4 of the studies included an adequate randomization process and concealment of allocation, and a priori sample size calculations were rare. Only few studies were blinded. The majority of the studies had a maximum follow-up of 12 months, and many reported only the positive results. The reviewers concluded that the lack of adherence to best practice in trial-based studies on effectiveness was overwhelming. There was a significant but very small overall effect on depressive symptoms in the caregivers, which should be interpreted with caution. The meta-analysis did not identify any significant effect in other outcome parameters. The authors concluded that there is a pressing need to ensure that supportive interventions at the development stage are accompanied by good quality randomized evaluation in which outcomes that are important for clinicians and carers are measured. Subsequently, at least 1 recent RCT on psychosocial intervention for family carers was unable to identify any effect on primary outcome variables [38].

Thus, there is a great need for randomized controlled studies, which takes into account these methodological considerations, and also for studies directed towards patients with mild dementia. The DAISY study meets all quality criteria established by the Cochrane group [21, 22].

\section{Summary of Strengths and Limitations}

In summary, the strengths of the present study are related to the quality of the rater-blinded RCT design, the focus on patients with mild dementia and their caregivers, the inclusion of patients as well as caregivers in the intervention programme, the multifaceted and semitailored design of the intervention, the long-term follow-up and the unique potentials for registry-based follow-up. In addition, the study collected also qualitative data, as there is a risk that important aspects of supportive interventions, such as perceptions and attitudes concerning the programme or staff members, adverse effects or the positive aspects of sharing experiences with others, may be overlooked in quantitatively designed studies. Therefore, experience must also be gained from qualitative studies, which may help design future quantitative studies $[34,39]$.
There are also limitations associated with the study. The study includes a broad range of patients with mild dementia and not only those with identified needs for psychosocial intervention, which could potentially lead to unexpected adverse effects of the intensive support programme. On the other hand, based on the inclusion criteria the patient group is selected with a high representation of patients with a supportive social network and may not adequately reflect the average population of $\mathrm{AD}$ patients. Because there is no established consensus on primary outcomes, the study is to some extent also explorative and will contribute to the design of future studies.

\section{Conclusion}

There is a lack of appropriately designed trials investigating the efficacy of psychosocial interventions for informal carers of patients with dementia, and only few studies have included interventions for the patients as well. The DAISY study is the largest study to date to investigate the efficacy of a multifaceted psychosocial intervention programme in patients with mild dementia and their caregivers using an RCT design. The study applies a novel semitailored approach to counselling integrated in a multifaceted programme. The results of the ongoing study will contribute to the evidence for psychosocial intervention and to the design of future interventions for patients with mild dementia and their carers.

\section{Acknowledgements and Funding}

The DAISY study was supported by the National Board of Social Services at the Ministry of Social Affairs, the Ministry of Health, the Danish Health Foundation and the Research council of the Copenhagen Hospital Cooperation. The authors have no conflicts of interest to report. We would like to thank all raters and assistants from the 5 counties and the following study coordinators and physicians in the 5 participating centres for their contributions to patient recruitment, intervention and data collection:

Ribe County: Esbjerg Hospital, Department of Psychiatry (Anna Marie Hansen, Johanne Christensen, Jørgen Jensen);

Ringkoebing County: Herning Hospital, Department of Psychiatry (Marianne Refslund, Birgitte Aagaard, Palle Lund) and Holstebro Hospital, Department of Psychiatry (Inge Lund Petersen, Finn Andersen);

Roskilde County: Roskilde Hospital, Department of Geriatrics (Dorte Dyre, Lisbeth Petersen, Birgitte Froelund, Lise Korbo, Ellen Holm) and Department of Neurology (Kurt Luedorff); 
Vestsjaelland County: Korsoer Hospital, Department of Geriatrics (Mette Lassen, Lars Laugesen) and Dianalund Hospital, Department of Psychiatry (Thyge Jensen, Ole Bjoern Skausig);

Copenhagen Capital area: Hvidovre Hospital, Department of Geriatrics (Lillian Moerk Joergensen), Amager Hospital, Department of Geriatrics (Suzanne Sanders), Bispebjerg Hospital, De- partment of Geriatrics (Claus Moe), Frederiksberg Community Health Care Center (Ingrid Lauridsen), Frederiksberg Hospital, Department of Psychiatry (Rene Klysner), Glostrup Hospital, Department of Neurology, (Jens Feilberg), Rigshospitalet, Department of Neurology (Ane Eckerman, Eva Illemann, Peter Johannsen).

\section{References}

1 Schulz R, O’Brien AT, Bookwala J, Fleissner $\mathrm{K}$ : Psychiatric and physical morbidity effects of dementia caregiving: prevalence, correlates and causes. Gerontologist 1995;35:771791.

-2 Ulstein I, Bruun Wyller T, Engedal K: High score on the Relative Stress Scale, a marker of possible psychiatric disorder in family carers of patients with dementia. Int J Geriatr Psychiatry 2007;22:195-202.

-3 Schulz R, Beach SR: Caregiving as a risk factor for mortality: the Caregiver Health Effects Study. JAMA 1999;282:2215-2219.

-4 Mittelman MS, Ferris SH, Shulman E, Steinberg G, Levin B: A family intervention to delay nursing home placement of patients with Alzheimer disease: a randomized controlled trial. JAMA 1996;276:1725-1731.

-5 Brodaty H, Green A, Koschera A: Meta-analysis of psychosocial interventions for caregivers of people with dementia. J Am Geriatr Soc 2003;51:657-664.

-6 Brodaty H, McGilchrist C, Harris L, Peters KE: Time until institutionalization and death in patients with dementia: role of caregiver training and risk factors. Arch Neurol 1993;50:643-650.

7 Sörensen S, Pinquart M, Duberstein P: How effective are interventions with caregivers? An updated meta-analysis. Gerontologist 2002;42:356-372.

-8 Pinquart M, Sörensen S: Helping caregivers of persons with dementia: which interventions work and how large are their effects? Int Psychogeriatr 2006;18:577-595.

-9 Acton GJ, Kang J: Interventions to reduce the burden of caregiving for an adult with dementia: a meta-analysis. Res Nurs Health 2001;24:349-360.

-10 Schulz R, O’Brien A, Czaja S, Ory M, Norris R, Martire LM, Belle SH, Burgio L, Gitlin L, Coon D, Burns R, Gallagher-Thompson D, Stevens A: Dementia caregiver intervention research: in search of clinical significance. Gerontologist 2002;42:589-602.

11 Pusey H, Richards D: A systematic review of the effectiveness of psychosocial interventions for carers of people with dementia. Aging Ment Health 2001;5:107-119.

-12 Cooke DD, McNally L, Mulligan KT, Harrison MJ, Newman SP: Psychosocial interventions for caregivers of people with dementia: a systematic review. Aging Ment Health 2001;5:120-135.
13 Brodaty H, Gresham M, Luscombe G: The Prince Henry Hospital dementia caregivers' training programme. Int J Geriatr Psychiatry 1997;12:183-192.

14 Mittelman MS, Ferris SH, Shulman E, Steinberg G, Ambinder A, Mackell JA Cohen J: A comprehensive support program: effect on depression in spouse-caregivers of $\mathrm{AD}$ patients. Gerontologist 1995;35:792-802.

15 Mittelman MS, Roth DL, Coon DW, Haley WE: Sustained benefit of supportive intervention for depressive symptoms in caregivers of patients with Alzheimer's disease. Am J Psychiatry 2004;161:850-856.

16 Mittelman MS, Brodaty H, Wallen AS, Burns A: A three-country randomized controlled trial of a psychosocial intervention for caregivers combined with pharmacological treatment of patients with Alzheimer disease: effects on caregiver depression. Am J Geriatr Psychiatry 2008;16:893-903.

17 Thompson CA, Spilsbury K, Halle J, Birks Y, Barnes C, Adamson J: Systematic review of information and support interventions for caregivers of people with dementia. BMC Geriatrics 2007;7:18.

- 18 Waldemar G, Phung KT, Burns A, Georges J, Hansen FR, Iliffe S, Marking C, Rikkert MO, Selmes J, Stoppe G, Sartorius N: Access to diagnostic evaluation and treatment for dementia in Europe. Int J Geriatr Psychiatry 2007;22:47-54.

19 Phung TK, Andersen BB, Kessing LV, Mortensen PB, Waldemar G: Diagnostic evaluation of dementia in the secondary health care sector. Dement Geriatr Cogn Disord 2009;27:534-542.

20 Moher D, Schulz KF, Altman DG; CONSORT Group (Consolidated Standards of Reporting Trials): The CONSORT statement: revised recommendations for improving the quality of reports of parallel group randomised trials. JAMA 2001;285:1987-1991.

21 Thompson CA, Spilsbury K, Barnes C: Information and support interventions for carers of people with dementia (protocol). Cochrane Database Syst Rev 2003;4:CD004513. DOI: 10.1002/14651858.CD004513.

22 Nelis S, Quinn C, Clare L: Information and support interventions for informal caregivers of people with dementia (protocol). Cochrane Database Syst Rev 2007;2:CD006440. DOI: $10.1002 / 14651858 . C D 006440$.
23 American Psychiatric Association (APA): Diagnostic and Statistical Manual of Mental Disorders. DSM-IV, ed 4. Washington, American Psychiatric Association, 1993.

- 24 McKhann G, Drachman D, Folstein M, Katzman R, Price D, Stadlan EM: Clinial diagnosis of Alzheimer's disease: report of the NINCDS-ADRDA Work Group under the auspices of Department of Health and $\mathrm{Hu}$ man Services Task Force on Alzheimer's Disease. Neurology 1984;34:939-944.

25 McKeith IG, Galasko D, Kosaka K, Perry EK, Dickson DW, Hansen LA, Salmon DP, Lowe J, Mirra SS, Byrne EJ, Lennox G, Quinn NP, Edwardson JA, Ince PG, Bergeron C, Burns A, Miller BL, Lovestone S, Collerton D, Jansen EN, Ballard C, de Vos RA, Wilcock GK, Jellinger KA, Perry RH: Consensus guidelines for the clinical and pathological diagnosis of dementia with Lewy bodies (DLB): report of the consortium on DLB international workshop. Neurology 1996;47:1113-1124.

26 Peavey VR: Sociodynamic Counselling: A Constructivist Perspective for the Practice of Counselling in the $21^{\text {st }}$ Century. Victoria, Trafford Publishing, 1997.

27 Ishiama FI: On self-validation. Trumpeter (online) 1993;10:2-8.

28 Sogaard R, Sorensen J, Waldorff FB, Eckermann A, Buss DV, Waldemar G: Private costs almost equal health care costs when intervening in mild Alzheimer's: a cohort study alongside the DAISY trial. BMC Health Serv Res 2009;9:215.

29 Dufouil C, Brayne C, Clayton D: Analysis of longitudinal studies with death and drop-out: a case study. Stat Med 2004;23:2215-2226.

30 Robins JM, Rotnitzky A, Zhao LP: Analysis of semiparametric regression models for repeated outcomes in the presence of missing data. J Am Stat Assoc 1995;90:106-121.

- 31 Seltzer B, Zolnouni P, Nunez M, Goldman R, Kumar D, Ieni J, Richardson S; Donepezil '402' Study Group: Efficacy of donepezil in early-stage Alzheimer disease: a randomized placebo-controlled trial. Arch Neurol 2004; 61:1852-1856.

32 Winblad B, Engedal K, Soininen H, Verhey F, Waldemar G, Wimo A, Wetterholm AL, Zhang R, Haglund A, Subbiah P, Donepezil Nordic Study Group: A 1-year randomized placebo-controlled study of donepezil in patients with mild to moderate AD. Neurology 2001;97:489-495. 
>33 Jonsson L, Andreasen N, Kilander L, Soininen $\mathrm{H}$, Waldemar $\mathrm{G}$, Nygaard H, Winblad B, Jonhagen ME, Hallikainen M, Wimo A: Patient- and proxy-reported utility in Alzheimer disease using the EuroQoL. Alzheimer Dis Assoc Disord 2006;20:49-55.

-34 Sørensen LV, Waldorff FB, Waldemar G: Early counselling and support for patients with mild Alzheimer's disease and their caregivers: a qualitative study on outcome. Aging Ment Health 2008;12:444-450.

-35 Sørensen LV, Waldorff FB, Waldemar G: Social participation in home-living patients with mild Alzheimer's disease. Arch Gerontol Geriatr 2008;47:291-301.

-36 Waldorff FB, Waldemar G: Self-rated health in patients with mild Alzheimer's disease: baseline data from the Danish Alzheimer Intervention Study. Arch Gerontol Geriatr 2010;50:1-5.

-37 Reynish E, Cortes F, Andrieu S, Cantet C, Olde Rikkert M, Melis R, Froelich L, Frisoni GB, Jönsson L, Visser PJ, Ousset PJ, Vellas B; ICTUS Study Group: The ICTUS study: a prospective longitudinal observational study on 1380 Alzheimer patients in Europe: study design and baseline characteristics of the cohort. Neuroepidemiology 2007;29:2938 .
38 Ulstein ID, Sandvik L, Wyller TB, Engedal K: A one-year randomized controlled psychosocial intervention study among family carers of dementia patients - effects on patients and carers. Dement Geriatr Cogn Disord 2007;24:469-475.

39 Lavoie J-P, Ducharme F, Lévesque L, Hebert R, Vezina J, Gendron C, Preville M, St-Laurent C, Voyer L: Understanding the outcomes of a psycho-educational group intervention for caregivers of persons with dementia living at home: a process evaluation. Aging Ment Health 2005;9:25-34.

40 Alexopoulos GS, Abrams RC, Young C, Shamolan CA: Cornell Scale for Depression in Dementia. Biol Psychiatry 1988:23;271284.

41 EuroQoL Group: EuroQoL - a new facility for the measurement of health-related quality of life. Health Policy 1990;16:199-208.

42 Folstein MF, Folstein SE, McHugh PR: 'Mini-Mental State' J Psychiatr Res 1975;12: 189-198.

43 Yesavage JA, Brink TL: Development and validation of a geriatric depression screening scale: a preliminary report. J Psychiatr Res 1983; 17:37-49.

44 Logsdon RG, Gibbons LE, McCurry S, Teri L: Quality of life in Alzheimer's disease: patient and caregiver report (QoL-AD). J Ment Health Aging 1999;5:21-32.
45 Cummings J, Mega M, Gray K, RosenbergThompson S, Carusi DA, Gornbeln J: The Neuropsychiatric Inventory: comprehensive assessment of psychopathology in dementia. Neurology 1994;44:2308-2314.

-46 Kaufer DI, Cummings JL, Ketchel P, Smith V, McMillan A, Shelley T, Lopez OL, DeKosky ST: Validation of the NPI-Q, a brief clinical form of the neuropsychiatric inventory. J Neuropsychiatry Neurosci 2000;12:233-239.

47 Galasko D, Bennett D, Sano M, Ernesto C, Thomas R, Grundman M, Ferris S, Alzheimer's Disease Cooperative Study: An inventory to assess activities of daily living for clinical trials in Alzheimer's disease. Alzheimer Dis Assoc Disord 1997;11(suppl 2):S33-S39.

-48 Reed RB, Jagust WJ, Coulter L: Anosognosia in Alzheimers disease - relationship to depression, cognitive function and cerebral perfusion. J Clin Exp Neuropsychol 1993;15: 231-244.

49 Wimo A, Wetterholm AL, Mastey V, Winblad B: Evaluation of healthcare resource utilization and caregiver time in anti-dementia drug trials; in Wimo A, Jönsson B, Karlsson G, Winblad B (eds): Health Economics of Dementia. Chichester, Wiley, 1998, pp 465-477. 